\title{
Evaluation of bone marrow in cases of pancytopenia in a tertiary care hospital
}

\author{
Vaidya $\mathrm{S}^{1}$ \\ ${ }^{I}$ Department of Pathology, Kathmandu Medical College, Kathmandu, Nepal.
}

\author{
Keywords: \\ Aplastic anemia; \\ Bone marrow; \\ Megaloblastic anemia; \\ Pancytopenia.
}

\begin{abstract}
Background: A spectrum of primary and secondary disorders that affect the bone marrow may manifest with pancytopenia. This study was carried out to identify the various causes of pancytopenia in patients attending a tertiary care hospital in Lalitpur, Nepal.

Materials and Methods: A descriptive study of 83 cases of pancytopenia was carried out in the Department of Pathology, Patan Academy of Health Sciences, Lalitpur, Nepal over a two year period from August 2010 to July 2012.

Results: Eighty three patients underwent bone marrow examination. Mean age of the patients was 34 years (range: 4 to 75 years). Maximum number of patients (31.33\%) was seen in the age group of 16 30 years. The commonest cause of pancytopenia was megaloblastic anemia which was seen in 34.94\% (29/83) cases followed by aplastic anemia and hematological malignancies in $31.32 \%$ (26/83) and 14.46\% (12/83) cases, respectively.

Conclusion: This study concluded that megaloblastic anemia and aplastic anemia were the two most common causes of pancytopenia. Bone marrow aspiration is an established diagnostic modality in the evaluation of pancytopenia.
\end{abstract}

\section{INTRODUCTION}

Pancytopenia is a descriptive term referring to a reduction in all three blood cell lineages: erythrocytes, leucocytes, and platelets. The underlying mechanisms are decrease in hematopoietic cell production, marrow replacement by abnormal cells, suppression of marrow growth and differentiation, ineffective hematopoiesis with cell death,

\footnotetext{
Correspondence:

Dr. Sujan Vaidya, $M D$

Department of Pathology,

Kathmandu Medical College, Kathmandu, Nepal.

E-mail:vaidyasujan@gmail.com
}

defective cell formation which are removed from the circulation, antibody mediated sequestration or destruction of cells and trapping of cells in a hypertrophied and overactive reticuloendothelial system. ${ }^{1}$

A spectrum of primary and secondary disorders that affect the bone marrow may manifest with pancytopenia. ${ }^{2}$ The presenting symptoms are often attributable to the anemia or thrombocytopenia. Leucopenia is often seen in the subsequent course of the disorder. ${ }^{3}$ Common clinical manifestations are pallor, fatigue, splenomegaly, lymphadenopathy, fever, bleeding, weight loss, hepatomegaly and jaundice. ${ }^{4}$ 
Determination of the underlying etiopathology of pancytopenia is crucial as it determines the management and prognosis of the patients. Bone marrow examination is extremely useful in the evaluation of pancytopenia. The present study was undertaken to identify the various causes of pancytopenia in patients attending a tertiary care hospital in Lalitpur, Nepal.

\section{MATERIALS AND METHODS}

This is a descriptive study conducted in the Department of Pathology, Patan Academy of Health Sciences, Lalitpur, Nepal over a 2 year period (August 2010 to July 2012). The inclusion criteria for pancytopenia were hemoglobin $(\mathrm{Hb})$ less than $10 \mathrm{gm} / \mathrm{dL}$, total leukocyte count (TLC) less than 4000 /cumm and platelet count less than 150000/cumm. Cases fulfilling the definition of pancytopenia but lacking marrow representative bone marrow in the marrow aspirate were excluded from the study.

In each case, bone marrow marrow aspiration was performed by the standard technique using Salah needle; from the posterior superior iliac crest under local anesthesia; taking standard aseptic precautions. Trephine biopsy was performed using Jamshidi needle whenever it was necessary. Bone marrow aspiration smears were stained with Wright stain. Special cytochemical stains such as Myeloperoxidase (MPO) and Periodic-acid Schiff (PAS) stains were also used when required.

Patient data was retrieved from the medical records which included age, gender, clinical findings, peripheral blood smear and bone marrow examination reports. The data gathered were used to determine the cause of pancytopenia and compared with other studies in the literature.

\section{RESULTS}

A total of 83 cases presenting of pancytopenia were included in the study. There were 47 males and 36 females with male: female ratio of 1.3:1. The age of the patients ranged from 4 to 75 years with a mean age of 34 years. The maximum number of patients $(31.33 \%)$ was seen in the age group of 16 - 30 years (Table 1$)$.

The clinical features of patients presenting with pancytopenia are shown in Table 2. Pallor was present in all the cases. The other common clinical features were generalized weakness and fever which were seen in $71.08 \%(59 / 83)$ and $55.42 \%$ (46/53) cases, respectively.

Megaloblastic anemia was the commonest bone marrow aspiration finding which was seen in 34.94\% (29/83) cases followed by aplastic anemia in $31.32 \%$ (26/83) cases (Table $3)$.
Table 1: Age distribution of the patients

\begin{tabular}{ccc}
\hline Age (years) & No. of cases & \multicolumn{1}{l}{$\%$} \\
\hline$<15$ years & 9 & 10.84 \\
$16-30$ years & 26 & 31.33 \\
$31-45$ years & 23 & 27.71 \\
$46-60$ years & 19 & 22.89 \\
$>60$ years & 6 & 7.23 \\
\hline Total & 83 & 100 \\
\hline
\end{tabular}

Table 2: Clinical features at presentation

\begin{tabular}{|lcc|}
\hline Clinical feature & No. of cases & Percentage \\
\hline Pallor & 83 & 100 \\
\hline Fever & 46 & 55.42 \\
\hline Generalised weakness & 59 & 71.08 \\
\hline Bleeding manifestations & 24 & 28.92 \\
\hline Hepatomegaly & 10 & 12.05 \\
\hline Splenomegaly & 15 & 18.07 \\
\hline Lymphadenopathy & 5 & 6.02 \\
\hline
\end{tabular}

Table 3: Bone marrow aspiration findings

\begin{tabular}{lcc}
\hline Diagnosis & No. of cases & Percentage \\
\hline Megaloblastic anemia & 29 & 34.94 \\
Erythroid hyperplasia & 11 & 13.25 \\
Aplastic anemia & 26 & 31.33 \\
\hline Acute leukemia & 8 & 9.64 \\
\hline Non-Hodgkin lymphoma & 2 & 2.41 \\
Leishmaniasis & 1 & 1.20 \\
Plasma cell myeloma & 2 & 2.41 \\
Metastatic tumour & 1 & 1.20 \\
\hline Normal bone marrow & 3 & 3.62 \\
\hline Total & $\mathbf{8 3}$ & $\mathbf{1 0 0}$ \\
\hline
\end{tabular}

Table 4: Comparison of age and sex distribution in other studies

\begin{tabular}{|cccc}
\hline \multicolumn{1}{c}{ Authors } & No. of cases & Age range (yrs) & M:F \\
\hline Khunger JM et al.6 & 200 & $2-70$ & $1.2: 1$ \\
\hline Gayathri BN et al.7 & 104 & $2-80$ & $1.2: 1$ \\
\hline Khodke K et al.8 & 50 & $3-69$ & $1.3: 1$ \\
\hline Kumar R et al.9 & 166 & $12-73$ & $2.1: 1$ \\
\hline Hirachand S et al.10 & 52 & $12-82$ & $1.2: 1$ \\
\hline Jha et al.11 & 148 & $1-79$ & $1.3: 1$ \\
\hline Present study & 83 & $4-75$ & $1.3: 1$ \\
\hline
\end{tabular}


Table 5: Common causes of pancytopenia in different studies

\begin{tabular}{|c|c|c|c|c|c|}
\hline Study & Country & Year & No. of cases & $\begin{array}{c}\text { Commonest cause } \\
(\%)\end{array}$ & $\begin{array}{l}\text { Second most common cause } \\
(\%)\end{array}$ \\
\hline Khunger et al.6 & India & 2002 & 100 & Megaloblastic anemia (72\%) & Aplastic anemia (14\%) \\
\hline Gayathri et al.7 & India & 2011 & 104 & Megaloblastic anemia (74.07\%) & Aplastic anemia (18.26\%) \\
\hline Khodke et al.8 & India & 2000 & 50 & Megaloblastic anemia (44\%) & Aplastic anemia (14\%) \\
\hline Hirachand et al.10 & Nepal & 2013 & 52 & Aplastic anemia (50\%) & Megaloblastic anemia (34.61\%) \\
\hline Jha et al.11 & Nepal & 2007 & 148 & Aplastic anemia ((29.05\%) & Megaloblastic anemia (23.64\%) \\
\hline Niazi et al.12 & Pakistan & 2004 & 89 & Aplastic anemia $(38.27 \%)$ & Megaloblastic anemia (24.7\%) \\
\hline Keisu et al.16 & $\begin{array}{l}\text { Israel and } \\
\text { Europe }\end{array}$ & 1990 & 100 & $\begin{array}{l}\text { Neoplastic disease, radiation } \\
(32 \%)\end{array}$ & Aplastic anemia (19\%) \\
\hline Pathak et al.17 & Nepal & 2010 & 102 & Aplastic anemia (42.15\%) & Hematological malignancies (19.4\%) \\
\hline Tilak et al.18 & India & 1999 & 77 & Megaloblastic anemia (68\%) & Aplastic anemia $(7.7 \%)$ \\
\hline Hossain et al.19 & Bangladesh & 1992 & 50 & Aplastic anemia & Chronic malaria and kalazar \\
\hline Present study & Nepal & 2015 & 83 & Megaloblastic anemia (34.95\%) & Aplastic anemia (31.33\%) \\
\hline
\end{tabular}

\section{DISCUSSION}

Pancytopenia is not an uncommon hematological problem encountered in clinical practice and should be suspected on clinical grounds when a patient presents with unexplained pallor, prolonged fever, and tendency to bleed. ${ }^{5}$ Bone marrow examination is a frequently requested investigation to determine the cause pancytopenia.

A total of 83 patients presenting with pancytopenia were included in the study. The age of the patients ranged from 4 to 75 years with a mean age of 34 years and a male: female ratio of 1.3:1. Age and sex distribution of the patients were compared to similar data in the literature (Table 4).

Pallor is a common clinical presentation in patients with pancytopenia and is universal in all patients. In our study, generalized weakness, fever and bleeding manifestations were the other common clinical findings which were seen in $71.08 \%$ (59/83), 55.42\% (46/53) and 28.92\% (24/53) cases, respectively. Similar observations were made by made Niazi et al. ${ }^{12}$ and Dahake et al. ${ }^{13}$ However, in other studies by Khodke et al. ${ }^{8}$ and Hamid et al. ${ }^{14}$ the commonest clinical features were fever, generalized weakness and bleeding manifestations, respectively.

The frequency of various diagnostic entities causing pancytopenia has been attributed to differences in methodology, stringency of diagnostic criteria, geographic area, period of observation, genetic differences, and varying exposure to cytotoxic drugs. ${ }^{15}$ The commonest causes of pancytopenia in other similar studies were mostly aplastic anemia or megaloblastic anemia (Table 5).

Megaloblastic anemia due to deficiency of Vitamin B12 and folic acid is now a well recognized and established cause of cytopenias. ${ }^{20}$ It can either present as bicytopenia or pancytopenia, or rarely with thrombocytopenia only. ${ }^{21}$
In our study, it was the commonest cause of pancytopenia. Similar observations were made in other studies from India. ${ }^{6-8,18} \mathrm{~A}$ high incidence of megaloblastic anemia in the Indian subcontinent seem to reflect a higher prevalence of nutritional deficiency. A possible explanation for the deficiency of Vitamin B12 and folic acid in this region could be due to the various chronic inflammatory disorders of the gut, like chronic diarrhoeas, parasitic infections and malabsorption states, apart from poor nutrition. ${ }^{5}$

Aplastic anemia was the second most common cause of pancytopenia in our study. Likewise, similar results have been obtained in the literature from Nepal and other countries from the subcontinent. ${ }^{10-12,17,19}$ It's pathogenesis is not fully understood. However, two major etiologies have been invoked: an immunologically mediated suppression and an intrinsic abnormality of stem cells. ${ }^{22}$

In this study, hematological malignancies accounted for $14.46 \%$ (12/83) of the cases of pancytopenia. Acute leukemia alone constituted $9.64 \%(8 / 83)$ cases of pancytopenia which is low compared to a similar study by Jha et al. $(19.59 \%)^{11}$ in contrast to a study by Kumar et al. ${ }^{9}$ where cases of acute leukemia were not detected. In other studies by Hirachand et al. ${ }^{10}$ and Pathak et al. ${ }^{17}$ acute leukemia accounted for $7.69 \%$ and $8.8 \%$, respectively. ${ }^{10,17}$

Acute lymphoblastic leukemia (ALL) and acute myeloid leukemia (AML) were seen in 2 and 6 cases, respectively. Both the cases of ALL were seen in children while all the 6 cases of AML were seen in adults. Non-Hodgkin lymphoma and plasma cell myeloma were the other two hematological malignancies seen in adults. Similar to other studies, both these malignancies were not seen in a significant number. $^{8-11,18}$

Erythroid hyperplasia was seen in $13.25 \%$ (11/83) cases of pancytopenia in this study. The relationship of erythroid 
hyperplasia to pancytopenia is uncertain. It is possible that some of these cases represent one phase in the evolution of hypoplasia, while some may be cases of refractory anemia. Hypercellular or normocellular marrow in cases of pancytopenia can also be seen in cases with ineffective hematopoiesis with cell death within the marrow. ${ }^{1}$

Leismaniasis was identified in one case in our study. It is one of the leading causes of pancytopenia. A higher incidence of pancytopenia has been reported in studies from the subcontinent. ${ }^{8,23} \mathrm{~A}$ case of a metastatic adenocarcinoma was also detected in bone marrow aspiration.

Normal bone marrow in pancytopenia was seen in 3.62\% $(3 / 83)$ cases. Similar data has been obtained by Jha et al. ${ }^{11}$ (3.38\%) and Pathak et al. ${ }^{17}$ (5.8\%). Normal bone marrow can be seen in pancytopenic patients as a result of sequestration and/or destruction of cells by the action of antibodies or trapping of normal cells in a hypertrophied and over-reactive reticuolendothelial system. ${ }^{24}$

\section{CONCLUSION}

Bone marrow aspiration is an established diagnostic modality in the evaluation of pancytopenia. The major differential diagnostic considerations of pancytopenia are aplastic anemia, megaloblastic anemia and hematological malignancies. Megaloblastic anemia can be prevented by improving the socioeconomic and nutritional status of our population.

\section{REFERENCES}

1. Williams DM, Pancytopenia, aplastic anemia and pure red cell aplasia, In: Lee RG, Foerster J, Lukens J, Paraskevas F, Greer JP, Rodgers GM (eds). Wintrobe's Clinical Hematology, 10th edn. William and Wilkins: Baltimore; 1997. pp 1449-84.

2. Williams WJ, Bentkr E, Erskv AJ. Haematology 3rd ed. McGraw Hill Book Company: Singapore; 1986. 184p.

3. Firkin F, Chesterman C, Penington D, Rush B. de Gruchy's Clinical Haematology in Medical Practice. 5th ed. Blackwell Scientific Publications: London; 1989. pp 119-136.

4. Tariq M, Khan N, Basri R, Amin S. Aetiology of pancytopenia. Professional Med J 2010;17:252-6.

5. Memon S, Shaikh S, Nizamani MAA. Etiological Spectrum of Pancytopenia Based on Bone Marrow Examination in Children J Coll Physicians Surg Pak. 2008;18:163-7. doi: 03.2008/JCPSP.163167

6. Khunger JM, Arculselvi S, Sharma U, Ranga S, Talib VH. Pancytopenia- A Clinico-hematological study of 200 cases. Indian J Pathol Microbiol 2002;45:375-9.

7. Gayathri B N, Kadam Satyanarayan Rao. Pancytopenia: A Clinico
Hematological Study. Journal of Laboratory Physicians 2011;3:1520. Crossref

8. Khodke K, Marwah S, Buxi G, Vadav RB, Chaturvedi NK. Bone marrow examination in cases of pancytopenia. J Academy Clin Med 2001;2:55-9.

9. Kumar R, Kalra SP, Kumar H, Anand AC, Madan M. Pancytopenia A six year study. J Assoc Physicians India 2001;49:1079-81.

10. Hirachand S, Singh R, Lama S. Frequency of causes of pancytopenia in a private hospital in Kathmandu. Health Renaissance 2013;11:1347. Crossref

11. Jha A, Sayami G, Adhikari RC, Panta AD, Jha R. Bone Marrow Examination in Cases of Pancytopenia. J Nepal Med Assoc 2008;47:12-7.

12. Niazi M, Raziq F. The incidence of underlying pathology in pancytopenia: an experience of 89 cases. J Postgrad Med Inst 2004;18:76-9.

13. Dahake V, Margam S, Gadgil N, Patil M, Kalgutkar A. Clinicohematological Analysis of Pancytopenia in a Tertiary Care Hospital. International Journal of Scientific Study 2014;2: 59-63.

14. Hamid GA, Shukry SAR. Patterns of pancytopenia in Yemen. Turk J Hematol 2008;25:71-4.

15. International agranulocytosis and aplastic anemia study. Incidence of aplastic anemia, the relevance of diagnostic criteria. Blood 1987;70:1718-21

16. Keisu M, Ost A. Diagnosis in patients with severe pancytopenia suspected of having aplastic anemia. Eur J Haematol 1990;45:11-4. Crossref

17. Pathak R, Jha A, Sayami G. Evaluation of bone marrow in patients with pancytopenia. Journal of Pathology of Nepal 2012;2:265 -71. Crossref

18. Tilak V, Jain R. Pancytopenia - A clinico-hematologic analysis of 77 cases. Indian J Pathol Microbiol 1999;42:399-404.

19. Hossain MA, Akond AK, Chowdhary MK et al. Pancytopenia- A study of 50 cases. Bangladesh Journal of Pathology 1992;1:912.

20. Chandra J, Jain V, Narayan S, Sharma S, Singh V, Kapoor AK, Batra S. Folate and cobalamin deficiency in megaloblastic anemia in children. Indian Pediatr 2002;39:453-7.

21. Jan MA. Thrombocytopenia in children. J Postgrad Med Inst 2004;18:353-8

22. Aster JC. Red Blood Cells and Bleeding Disorders, In: Robbins and Cotran (eds). Pathologic Basis of Disease. 7th ed. Saunders: 
Philadelphia, Pennsylvania; 2004. pp619-59.

23. Dhingra KK, Gupta P, Saroha V, Setia N, Khurana NN, Singh T. Morphological findings in bone marrow biopsy and aspirate smears of visceral kala azar: A review. Indian J Pathol Microbiol 2010;53:96100. Crossref
24. Kumar DB, Raghupathi AR. Clinicohematologic analysis of pancytopenia: Study in a tertiary care centre. Basic and Applied Pathology 2012;5:19-21. Crossref 